\title{
2006-2585: PREDICTING STUDENT PREPAREDNESS IN CALCULUS
}

Jenna Carpenter, Louisiana Tech University

JENNA P. CARPENTER is Academic Director of Mechanical Engineering, Chemical

Engineering, Civil Engineering and Construction Engineering Technology; Wayne and Juanita

Spinks Professor; and Associate Professor of Mathematics at Louisiana Tech University. She was co-developer of the math sequence for the integrated engineering curriculum at Tech and currently leads an effort to develop an integrated science curriculum for math, science and education majors.

\section{Ruth Ellen Hanna, Louisiana Tech University}

RUTH ELLEN HANNA is Walter E. Koss Professor of Mathematics and Coordinator for Undergraduate Mathematics at Louisiana Tech University. She has coordinated mathematics placement assessment at Tech for over 25 years and has led the effort to implement web-based tutoring in mathematics. Currently, she is developing and teaching math courses via the internet. 


\title{
Predicting Student Preparedness in Calculus A Preliminary Report
}

\begin{abstract}
Five years ago Louisiana Tech University began using a web-based tutorial program, ALEKS, in an effort to provide more effective mathematics tutoring for its students. Results on performance indicate that, for students in Math 240 (our Calculus I), strong student use of ALEKS highly correlates with student retention and success. Moreover, data shows that approximately 1500 mathematics students (at the level of calculus and below) are using ALEKS each term. At present, students are placed into Calculus I based on their Math ACT score, although there are always students whose Math ACT scores and success in Calculus I do not correlate well. Students are permitted to take the ACT multiple times and use their highest score for placement. Because Louisiana implemented high-stakes standardized testing seven years ago in the public school system for $3^{\text {rd }}$ through $12^{\text {th }}$ grades, many students are now approaching the ACT with a substantial amount of long-term training and practice in taking standardized tests. Therefore, we wanted to investigate whether or not the Math ACT score is still a sufficiently accurate method of placement into Calculus I. This study looks at student performance on the initial ALEKS assessment to see if it might be a more accurate predictor of student success in Calculus I than the Math ACT or if it, together with the Math ACT, might be more reliable than the Math ACT data alone. In this preliminary report, we focus on whether or not the Math ACT accurately reflects student preparedness for calculus.
\end{abstract}

\section{Background}

Five years ago the Mathematics Program at Louisiana Tech University began using a web-based tutorial program marketed by McGraw-Hill entitled ALEKS (Asssessment and LEarning in

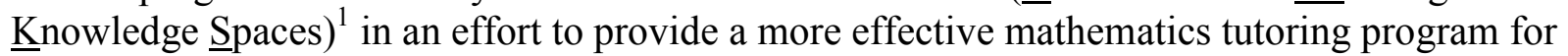
our students. The goals were to 1) increase student retention and success in freshman and sophomore-level mathematics courses (such as calculus, which all engineering majors take), and 2) increase the willingness of students to utilize the available tutorial services. Note that "student success" is defined as "making an "A", "B" or " $\mathrm{C}$ " in the course" (since all engineering and science majors are required to earn a grade of " $\mathrm{C}$ " or higher in all math courses which are prerequisites for other courses).

ALEKS is a web-based system (versus software-based) that can be accessed from any computer with web access and a java-enabled web browser. The ALEKS syllabus for each course is aligned with the actual content of the syllabus for the corresponding course at our university. Students who purchase an ALEKS access code and are provided a course code by the instructor of their mathematics class can then access the ALEKS program for that course via the internet from any computer 24 hours a day for the entire term. After completing the initial log-on process, students are required to take an initial assessment in ALEKS to determine their level of concept mastery. All work in ALEKS requires that the student work the problem and enter the resulting solutions. There are no multiple-choice or true-false questions. This initial assessment measures both mastery of prerequisite material and course content for the course in which the student is enrolled. Based on the student's performance on the initial assessment, ALEKS 
provides online tutorial instruction and associated practice problems (called Learning Mode) that start "where the student is" and work toward student mastery of the course syllabus.

Periodically, ALEKS will have the student complete a new assessment (of both prerequisite material and course content) in order to maintain an accurate evaluation of that student's needs and abilities. ALEKS provides a detailed progress history for each student, which includes hours spent using ALEKS and percent of content covered on both prerequisite material and course content, at any time.

ALEKS is a mandatory component of the course for every student who enrolls in Math 240-241, "Mathematics for Engineering and Science I \& II" (our Calculus I and II courses). We encourage students to spend at least 3 hours and make at least $6 \%$ progress on ALEKS outside of class each week. Each instructor has some discretion as to how the ALEKS grade counts toward the class grade. Data on student performance indicates that strong student use of ALEKS in Math 240 does highly correlate with both student retention and success, not only in Calculus I (see Table 3) and Calculus II, but throughout the entire freshman-sophomore calculus and differential equations sequence ${ }^{2}$. A working theory is that some of this behavior may be attributable to the fact that mathematically stronger and/or mature students, who would have likely been successful even without ALEKS, are the ones taking advantage of the opportunity to boost their skills via ALEKS. Data also indicates that students are using ALEKS in far greater numbers (approximately 1500 students per term for all mathematics courses at the level of calculus and below) than any other tutorial program we have ever had at our university, including come-and-go tutoring sessions and the more formal Supplemental Instruction program (both of which averaged $10-20$ students per day total from all lower-level mathematics courses, including calculus). We now have students using ALEKS almost 24 hours per day, 7 days per week (the only time we see very few students logged on is between 4:00 a.m. and 6:00 a.m.). ${ }^{2}$

\section{Predicting Student Preparedness for Calculus}

In order to be eligible to enroll in Math 240, our Calculus I, a student must either i) have at least a Math ACT of 26 or higher; ii) pass the Math 240 Credit Exam, or iii) successfully complete Math 101, College Algebra, with a grade of "C" or higher. The vast majority of students satisfy either criteria i) or iii). Students who successfully complete College Algebra are usually encouraged to take Math 112, Trigonometry, prior to enrolling in Math 240, although it is not at present a requirement. It has been our observation that students who first take trigonometry are more likely to be successful in calculus than those who go directly from college algebra to calculus.

Approximately eight years ago, our department determined the current Math ACT cut-off score of 26 by looking at the previous five years of data on students, their Math ACT score, and their success in their first college math course (again, success here is defined as making a " $\mathrm{C}$ " or higher). A majority of students with a Math ACT of 26 or higher were able to successfully complete Math 240 on their first try. It has been observed, however, that students with a Math ACT of $24-25$ often do better in Math 240 (after first having successfully completed Math 101 and perhaps Math 112 also) than those with a Math ACT of 26-27. This is likely due to the fact that the Math 24-25 group have stronger algebra and trigonometry skills by virtue of having taken college algebra and trigonometry prior to taking Calculus I. 
Students are allowed to re-take the ACT multiple times and are allowed to use their highest Math ACT score for math placement. Anecdotal feedback from students suggests that some students may take the ACT and spend all of their time on the mathematics portion of the ACT in an effort to improve their Math ACT score. Third party prep courses and materials are also available to help students increase their scores. Perusing student ACT data from Fall 2005 revealed students with as much as a 5-point difference in Math ACT scores from one test attempt to the next, although most fluctuations were at most 1 or 2 points. At our university, as at most, scholarships, admittance to the honors program, etc., depend, at least in part, on ACT scores. Studies have shown that short-term programs and training only boost the Math ACT score by 0 to 0.4 point, on average. ${ }^{3}$ Studies have also shown that additional instruction (such as taking another mathematics course) is the most effective way to increase test scores, such as the ACT. ${ }^{4}$

Starting in 1999, Louisiana (from which the majority of our students come) implemented a comprehensive accountability program in which standardized tests linked to the state assessment standards play a major role. High stakes standardized tests (equivalent to the National Assessment of Education Progress or NAEP tests) in $4^{\text {th }}, 8^{\text {th }}, 10^{\text {th }}$ and 11 th grades determine whether students are allowed to matriculate to the next grade. In $3^{\text {rd }}, 5^{\text {th }}, 6^{\text {th }}, 7^{\text {th }}$ and $9^{\text {th }}$ grades, the state administers the IOWA Tests as the state's norm-referenced tests. The NAEP-equivalent and IOWA test scores constitute $90 \%$ of each public school's annual performance score (SPS). An SPS of below 30 or failure to reach a biannual SPS growth target together with an SPS of below 100 automatically triggers progressively more intense levels of corrective action for the school. Schools that meet their growth targets and show improvement in scores of students classified as coming from high poverty backgrounds are eligible for monetary rewards and recognition ${ }^{5}$. Consequently, the public schools must devote time and attention to preparing students to take and perform their best on these standardized tests. Whether or not this prolonged emphasis and training from $3^{\text {rd }}-12^{\text {th }}$ grade affects performance on the standardized tests, such as the ACT and SAT, is not known.

There are always students whose Math ACT score and performance in Calculus I do not correlate. This has led faculty to question whether or not the number of these students has climbed in the last two to three years because of the combined effect of students taking the ACT multiple times and the long-term emphasis and training on standardized tests in the public school system. This study looks at student performance on the initial ALEKS assessment to see if it might be a more accurate predictor of student success in Calculus I than the Math ACT or if it, together with the Math ACT, might be more reliable than the Math ACT data alone. In this preliminary report, we focus on whether or not the Math ACT accurately reflects student preparedness for calculus.

\section{A Comparison of Math ACT Scores, ALEKS Initial Assessments and Course Grades}

One measure of student preparedness and prerequisite knowledge in Math 240, our Calculus I, is the student's score on the initial ALEKS assessment. Students are asked to take their initial ALEKS assessment during the first week of classes. Moreover, they are taking the assessment "cold", that is, without reviewing or studying for the assessment. In the Fall Quarter, the majority of students in Math 240 are either first time freshman (who have not taken a math class 
since spring or, in some cases, the previous fall) or students who have come directly from either Math 101 or Math 112 (the majority of whom took that math class in the spring). For both of these reasons, a score of $20 \%$ or more on the initial assessment usually indicates a strong student, even though the assessment covers what is supposed to be prerequisite knowledge for the course. A score of less than $10 \%$ on the initial assessment usually correlates with poor preparation for and poor performance in the course.

For Fall 2005, we collected the following data on all Math 240 students: highest Math ACT score, initial ALEKS assessment score, their final ALEKS assessment score and the final percent of ALEKS content mastered in learning mode (students may have been between assessments at the end of the course since these are automatically prompted when students make reasonable progress in learning mode). Of the 297 students enrolled in Math 240 in Fall 2005, 247 completed the initial ALEKS assessment. 50 students either did not register on ALEKS or started but did not complete the initial ALEKS assessment. The data is summarized below:

\begin{tabular}{|c|c|c|c|}
\hline MATH ACT & $\begin{array}{c}\text { AVERAGE } \\
\text { INITIAL } \\
\text { ASSESSMENT }\end{array}$ & $\begin{array}{c}\text { AVERAGE } \\
\text { FINAL } \\
\text { ASSESSMENT }\end{array}$ & $\begin{array}{c}\text { AVERAGE } \\
\text { FINAL } \\
\text { LEARNING }\end{array}$ \\
\hline $\begin{array}{c}\mathbf{3 3 - 3 6} \\
(12 \text { STUDENTS) }\end{array}$ & $19.5 \%$ & $69 \%$ & $74 \%$ \\
\hline $\begin{array}{c}\mathbf{3 2} \\
\text { (7 STUDENTS) }\end{array}$ & $16.6 \%$ & $65 \%$ & $71 \%$ \\
\hline $\begin{array}{c}\mathbf{2 8 - 3 1} \\
(87 \text { STUDENTS) }\end{array}$ & $14.9 \%$ & $53 \%$ & $58 \%$ \\
\hline $\begin{array}{c}\mathbf{2 6 - 2 7} \\
\text { (74 STUDENTS) }\end{array}$ & $11 \%$ & $36 \%$ & $41 \%$ \\
\hline $\begin{array}{c}\mathbf{2 4 - 2 5} \\
(23 \text { STUDENTS) }\end{array}$ & $15.7 \%$ & $39 \%$ & $44 \%$ \\
\hline $\begin{array}{c}\mathbf{1 9 - 2 3} \\
(21 \text { STUDENTS) }\end{array}$ & $9.3 \%$ & $34 \%$ & $39 \%$ \\
\hline $\begin{array}{c}\mathbf{1 4 - 1 8} \\
\text { (9 STUDENTS) }\end{array}$ & $5.7 \%$ & $24 \%$ & $27 \%$ \\
\hline $\begin{array}{c}\text { NO ACT SCORE } \\
\text { ON FILE } \\
\text { (14 STUDENTS) }\end{array}$ & $10 \%$ & $46 \%$ & $54 \%$ \\
\hline
\end{tabular}

Table 1 - Math ACT Score versus Performance on ALEKS Assessments

Note that these percentages do represent percent of problems worked correctly. Also, observe that all of the average initial ALEKS assessments are below 20\%. Moreover, those students in the 26-27 Math ACT category, as well as those with a Math ACT of 23 and below, scored poorly on the initial assessment. The students in the 24-25 Math ACT range scored better on the initial assessment than those in either the 26-27 Math ACT range or the 28-31 Math ACT range (which together contain approximately $2 / 3$ of the Math 240 students). The students in the 24-25 Math ACT range also achieved a higher final ALEKS assessment and higher final learning mode score than the 26-27 Math ACT group. 
Table 2, below, compares course grade with initial and final ALEKS assessments, final learning mode percentage and number of hours spent on ALEKS. With a ten-week term, students often spend their time the first week taking the ALEKS assessment and the last week taking final exams (there are no separate exam days), which leaves approximately 8 weeks of the term for students to work on ALEKS. Consequently 3 hours a week for 8 weeks works out to a total of 24 hours spent on ALEKS. Here, note that the "D", "F" and "W" student (i.e., those who were unsuccessful in the course) have average initial ALEKS assessments of the $10 \%$ or below.

\begin{tabular}{|c|c|c|c|c|}
\hline \multicolumn{5}{|c|}{ MATH 240 FALL 2005 } \\
\hline $\begin{array}{c}\text { SOURSE } \\
\text { GRADE }\end{array}$ & $\begin{array}{c}\text { AVERAGE } \\
\text { INITIAL } \\
\text { ASSESSMENT }\end{array}$ & $\begin{array}{c}\text { AVERAGE } \\
\text { FINAL } \\
\text { ASSESSMENT }\end{array}$ & $\begin{array}{c}\text { AVERAGE } \\
\text { FINAL } \\
\text { LEARNING }\end{array}$ & $\begin{array}{c}\text { AVERAGE } \\
\text { HOURS } \\
\text { ON ALEKS }\end{array}$ \\
\hline $\begin{array}{c}\text { A } \\
\text { (51 STUDENTS) }\end{array}$ & $18.25 \%$ & $68.37 \%$ & $73.06 \%$ & 25.45 \\
\hline $\begin{array}{c}\text { B } \\
\text { (54 STUDENTS) }\end{array}$ & $14.72 \%$ & $53.61 \%$ & $59.80 \%$ & 24.19 \\
\hline $\begin{array}{c}\text { C } \\
\text { (57 STUDENTS) }\end{array}$ & $11.98 \%$ & $42.46 \%$ & $48.61 \%$ & 18.96 \\
\hline $\begin{array}{c}\text { D } \\
(28 \text { STUDENTS) }\end{array}$ & $10.18 \%$ & $34.57 \%$ & $40.29 \%$ & 18.35 \\
\hline $\begin{array}{c}\text { F } \\
(20 \text { STUDENTS) }\end{array}$ & $9.45 \%$ & $26.75 \%$ & $31.75 \%$ & 15.33 \\
\hline W & $8.70 \%$ & $18.54 \%$ & $23.41 \%$ & 7.92 \\
\hline
\end{tabular}

Table 2 - Math 240 Course Grade versus Performance on ALEKS Assessments

Also note that only the " $A$ " and "B" students spent, on average, the required 24 hours (or more) on ALEKS during the term.

As in our earlier study, Table 3, below, shows that students who spend at least 3 hours a week (for 8 weeks) on ALEKS (i.e., 23.5 hours or more) are approximately twice as likely to successfully complete the course (that is, make an "A", "B" or "C" $\mathrm{C}$ ) as those who do not:

\begin{tabular}{|l|c|c|}
\hline \multicolumn{3}{|c|}{ MATH 240 FALL 2005 } \\
\hline \multicolumn{3}{|c|}{} \\
\hline All enrolled in Math 240 (297 students) & $60 \%$ & D-C-W \\
\hline Less than 23.5 hours ALEKS usage (188 students) & $45 \%$ & $55 \%$ \\
\hline 23.5 or more hours ALEKS usage (109 students) & $86 \%$ & $14 \%$ \\
\hline
\end{tabular}

Table 3 - Math 240 Fall 2005 Grades versus Time Spent on ALEKS

\section{Data Analysis}

We are in the process of collecting and analyzing the initial ALEKS assessment, Math ACT and course letter and numerical grade. We present the results thus far. 
Initial ALEKS Assessments vs. Course Grade - We took the data from Table 2 and compared the ALEKS initial assessment and course grade. The initial assessment percentages were grouped into seven groups: [24,28], [20,23], [16,19], [12,15], [8,11], [4,7], and [0,3]. The response variable was course grade. To determine if the initial assessment groups have a significant effect on course grades, we ran a Kruskal-Wallis nonparametric test on grade ranks. The analysis showed that the group effect on grades was highly significant, with a chi-square value of 55.2510 with 6 degrees of freedom and a p-value of less than 0.0001 . We also did a nonparametric multiple comparison test among mean ranks for the seven initial assessment groups. The results showed that students with an initial ALEKS assessment score in groups [20,23] and [24,28] had significantly higher course grades than those in groups $[8,11],[4,7]$ and $[0,3]$. This means that those with a higher initial ALEKS assessment score earned higher grades in the class.

Math ACT Scores vs. Initial Assessment - We took the data from Tables 1 and 2 and compared Math ACT score and ALEKS initial assessment. The Math ACT scores were grouped into seven groups: [33,36], [32], [28,31], [26, 27], [24,25], [19,23], and [14,18]. The response variable was initial assessment. As with the ALEKS initial assessment data, we ran a Kruskal-Wallis nonparametric test on initial assessment ranks to determine if the Math ACT groups have a significant effect on initial assessment. The analysis showed that the group effect on initial assessment was significant, with a chi-square value of 53.8302 with 6 degrees of freedom and a p-value of less than 0.0001. That is, a high Math ACT did correlate with a high initial ALEKS assessment score. We also did a regression of initial assessment on Math ACT and obtained an r-square value of 0.1402, which was significant, but indicates that the Math ACT is not a good predictor for the initial assessment score. Lastly, we did a nonparametric multiple comparison test among mean ranks for the seven Math ACT groups. The results showed that those students with a Math ACT of [33,36] and [32] differed significantly in their initial ALEKS assessment only from those students with a Math ACT of $[14,18]$. This means that the Math ACT is not as clear an indicator of preparedness as the initial ALEKS assessment.

We are in the process of gathering data to compare the Math ACT score and the course grade (percentage). With this information, we can compare how well the Math ACT and initial ALEKS assessment predict success in calculus.

\section{Conclusions}

Thus far, the data shows that a higher initial ALEKS assessment score does correspond to higher grades in Math 240 and that students with an initial ALEKS assessment of over 20 had significantly higher course grades than those with an initial ALEKS assessment of 11 and below. The data indicates that the Math ACT, however, is not a good predictor for the initial ALEKS assessment. The only Math ACT groups in which there was a significant difference in initial ALEKS assessment were the very lowest (14-18) and the very highest (32-26) groups. Since there were only 9 and 19 students (out of 247) in each of these groups, respectively, this suggests that for the vast majority of Math 240 students, those with a Math ACT of $19-31$ or 205/247 students, the Math ACT score does not accurately reflect their level of preparedness for the calculus course. Further comparisons of Math ACT and course grade will hopefully shed light on whether or not the Math ACT is indeed a reliable predictor of success in calculus. 


\section{Acknowledgements}

We would like to thank the faculty in our Mathematics Program and in Engineering at Louisiana Tech University who have used ALEKS in their courses, as well as our Associate Dean for Undergraduate Studies, Dr. Jim Nelson, for their support and assistance in our efforts. We would also like to acknowledge our faculty statistician, Dr. Raja Nassar, and his student, Ms. Mihaela Paun, for assistance in analyzing the data from this study.

\section{Bibliography}

1. ALEKS, Math for Colleges and Universities, General Information, http://www.highedmath.aleks.com/about/Welcome-ENGLISH.html.

2. Carpenter, Jenna and Ruth Ellen Hanna, Using a Web-Based Tutorial System to Improve Student Success in Calculus, in preparation.

3. Briggs, Derek C., The Effect of Admissions Test Preparation: Evidence form NELS:88, Chance, vol. 14, no.1, 2001, pg. $10-18$.

4. Scholes, Roberta J., and M. Margaret Lain, The Effects of Test Preparation Activities on ACT Assessment Scores, Annual Meeting of the AERA, Chicago, IL, March 1997.

5. Louisiana's School and District Accountability System,

http://www.doe.state.la.us/DOE/account/Policy/acctfram.html. 